\title{
Experimental study on micro-milling of Ti6Al4V with minimum quantity lubrication
}

\section{Xiaohu Zheng, Zhiqiang Liu and Ming Chen*}

School of Mechanical Engineering,

Shanghai Jiao Tong University,

800 Dongchuan RD. Minhang District,

Shanghai, 200240, China

Fax: +86-21-34206317

E-mail: wuxizhengxiaohu@hotmail.com

E-mail:99422120@163.com

E-mail: mchen@sjtu.edu.cn

*Corresponding author

\section{Xibin Wang}

School of Mechanical Engineering,

Beijing Institute of Technology,

5 South Zhongguancun Street,

Haidian District, Beijing, 100081, China

E-mail: Cutting0@bit.edu.cn

\begin{abstract}
The micro-milling of titanium alloy is a challenging task. Minimum quantity lubrication (MQL) is an eco-friendly coolant and low cost method for manufacturing compared with traditional coolant method. This paper studied the micro-milling mechanism of titanium alloy by analysing the tool wear, tool life, cutting vibration, surface finish and burr formation under MQL and dry cutting conditions. Experimental results show that MQL method in micro-milling will significantly improve tool life and reduce material adhesion. In order to study the influence of air fluid on micro-milling process, cutting vibration signal and surface morphology under different air fluid parameters were measured and analysed. Analysis results indicate that the air fluid direction of $180^{\circ}$ and $0^{\circ}$ aggravate tool vibration and lead to poor surface quality compared with the direction of $270^{\circ}$ and $90^{\circ}$. Air pressure also has great influence on tool vibration and burr formation. The burr size under $0.45 \mathrm{MPa}$ is bigger than other air pressures.
\end{abstract}

Keywords: micro-milling; MQL; dry milling; titanium alloy; tool wear; cutting vibration; FFT analysis; surface roughness; micro-burr; fluid direction; air pressure.

Reference to this paper should be made as follows: Zheng, X., Liu, Z., Chen, M. and Wang, X. (2013) 'Experimental study on micro-milling of Ti6A14V with minimum quantity lubrication', Int. J. Nanomanufacturing, Vol. 9, Nos. 5/6, pp.570-582. 
Biographical notes: Xiaohu Zheng is a candidate for PhD at Shanghai Jiao Tong University. He received his Bachelor degree and Master degree at the Jiangnan University, China. His research interests include micro-cutting technology, and precision manufacturing.

Zhiqiang Liu is a candidate for $\mathrm{PhD}$ at the Shanghai Jiao Tong University. His research interests include cutting technology and precision manufacturing.

Ming Chen is a Professor of Shanghai Jiao Tong University. His research interests include high-speed cutting technology, micro and precision manufacturing. He is a member of ICAT and the editorial boards of International Journal of Precision Engineering and Manufacturing and International Journal of Nanomanufacturing.

Xibin Wang is a Professor of Beijing Institute of Technology. His research interests include high-speed cutting technology and micro manufacturing technology.

This paper is a revised and expanded version of a paper entitled 'Experimental study on micro-milling of Ti6Al4V with minimum quantity lubrication' presented at International Conference of Nanoman2012, Tokyo, July 2012.

\section{Introduction}

Eco-friendly machining methods play important role in sustainable manufacturing technology. In general, cutting fluids have been applied to cool and lubricate in machining process. However, the cutting fluids often cause environmental problems. In order to reduce environmental pollution caused by traditional liquid coolant, some special cooling methods have been developed to instead traditional cooling methods, such as minimum quantity lubrication, solid lubrication and dry cutting technology.

Minimum quality lubrication (MQL), which is also called near dry cutting, is a method that uses little quality of coolant in machining, where the flow rate could be lower than $10 \mathrm{mml} / \mathrm{h}$. Cold water mist jet cooling method (CWMJ) was used during titanium alloy turning experiments and acceptable surface quality and chip morphology were obtained. The experimental results indicate that CWMJ has better cooling effect when compared with cold air jet and flood cooling method (An et al., 2011). In another research, cryogenic pneumatic mist jet (CPMJ) technology was used to enhance the heat transfer in grinding zone during grinding of titanium alloy. High speed cold water mist with jet was made by special setup and sprayed to grinding zone. Experimental results showed that heat transfer efficiency was better than cold air jet method and flood cooling method (An et al., 2010). An atomisation-based cutting fluid application system was designed to ensure spreading of droplets on the workpiece surface for micro milling. Ultrasonic vibration method was used to make the fluid break up into fine droplets with proper size. The cutting experiments showed that better chip evacuation, lower cutting temperature and cutting forces were achieved compared with dry and flood cooling methods (Jun et al., 2008). The performance of MQL to dry condition on tool wear and surface roughness for micro-milling of SKD 61 steel was investigated by researchers. Results indicate that micro-milling with MQL obtained better surface roughness and less burr formation than dry milling, and tool wears were also decreased (Li and Chou, 2010). 
Nanofluid MQL technology is a new technology which is different from conventional MQL technology. Nanofluid is a fluid which contains nano-particles, such as diamond, $\mathrm{MoS}_{2}$ and $\mathrm{Al}_{2} \mathrm{O}_{3}$. Nam et al. studied the micro-drilling process with nanofluid MQL shows difference. Experimental results showed that Nanofluid MQL significantly increases the tool life and reduces the drilling forces. In addition, the drilling quality is improved (Nam et al., 2011). The droplet behaviour on a rotating surface for atomisation-based cutting fluid is different from conventional fluid. A fluid with low surface tension and low velocity is proper for cooling cutting zone, whereas a fluid with low surface tension and high velocity is proper for lubrication (Ghai et al., 2010).

The high accuracy micro-components have been widely used in many industries, such as electronics, aerospace, automobile and biomedical. In nowadays, micro-cutting has become a common process in micro-nano manufacturing. Micro-milling and micro-drilling can meet the need of micro-features manufacturing in many industries (Chae et al., 2006). The researches on micromachining focus on cutting mechanism, machining quality, tool wear and developing new micro tools. The plastic deformation process of chip formation during micro-cutting of medium carbon steel is influenced by micro-structures An FE model was developed to illustrate the chip deformation process (Simoneau et al., 2006). Surface generation in micro-machining is also related to the micro-structures of work material. The surface generation process in the micro-end milling of both single-phase and multi-phase materials is different. A model was developed to predict surface generation in micro-milling based on the minimum chip thickness concept (Vogler et al., 2004). Vibration-assisted technology has been applied in micro-machining. A micro-machine for vibration-assisted micro-machining has been developed by researcher. The results of vibration-assisted micro-milling tests showed that surface roughness was improved (Ibrahim et al., 2011). An improved Victor and Kienzle model was developed to predict micro-cutting forces. The influence of cutting edge radius was taken into account in this modified model (Fleischer et al., 2009). FE method has been widely used in investigating micro-machining process. An FE model predicted the effect of cutting edge radius on micromachining was developed. The simulation results showed that the ratio of undeformed chip thickness to tool edge radius $(a / r)$ is a dominant factor in micromachining. When $a / r<1$, concentrated shear can not be observed in primary zone (Woon et al., 2008). The micro-cutting process can be divided into two types, i.e., ploughing and cutting. A method was developed to detect the ploughing during micro-milling through cutting force signal. Undecimated wavelet transform multi-resolution analysis was applied to detect the appearance of ploughing. The micro-milling experimental results showed that this method can be used for detecting ploughing in micro-machining (Yun et al., 2011). Acoustic emission signals was also applied in tool condition monitoring and showed a very short reaction time (Jemielniak and Arrazola, 2008; Mian et al., 2011). Tool life estimation during micro-milling process can be achieved by genetic algorithm-based parameter estimation approach. The results of verification tests showed that this method was convenient for online tool wear monitoring (Bao and Tansel, 2000). Chatter in micro-machining process limits tool life, machining quality and tolerances. The chatter theory developed for macro-machining is not proper for analysing micro-machining operation (Novakov and Jackson, 2009). Deburring is a time-consuming thing in machining titanium alloys. In order to reduce the top burr formation in micro-milling slots, the side angle can be enlarged in two ways: one, by changing the work geometry and two, by adding a taper to the milling tool. The 
enlarged side angle can strengthen the edge and then reduce the burr formation (Saptaji et al., 2012).

Hard-to-machining materials such as titanium alloy and hardened steel have been widely used in micro-equipments or micro features, such as micro-hole, micro-wall. The titanium alloy types include $\alpha$ and near $\alpha$ alloys, $\alpha / \beta$ alloys and the $\beta$ alloys. Ti6Ai4V, investigated in this paper, is $\alpha / \beta$ alloys. This alloy has good combination of mechanical properties (Boyer, 1996). In traditional micro-cutting process, titanium alloys have poor machinability due to many inherent properties as follows:

1 poor thermal conductivity leads to high temperature in cutting zone

2 chemically reactive properties lead to chipping and premature tool failure

3 high strength and low modulus of elasticity will further accelerate tool failure

(Ezugwu and Wang, 1997).

The micro-cutting system can be taken as a kind of weak stiffness system. Any outer disturbance would influence the machining qualities. Under the condition of micro-machining with MQL, the oil mist of MQL can be seemed as a disturbance factor to micro-tools. This paper aims to study the effects of MQL on tool wear, surface quality and vibration during micro-milling of titanium alloy. Micro-milling experiments were conducted compared with dry cutting tests. Tool life curves of two conditions were presented and tool wear mechanism was studied by SEM photos and EDS analysis. In order to analyse the effects of cutting fluid on cutting vibration and burr formation, a series of cutting tests with different fluid directions were conducted. Cutting vibration was studied by FFT analysis of vibration signals. Micro-burrs were captured by microscope.

\section{Experimental procedures}

The experimental setup of micro-cutting machine is shown in Figure 1. This machine consists of a three-axis motion table (working area $100 \times 100 \mathrm{~mm}$, linear motor with $0.1 \mu \mathrm{m}$ resolution), a gantry frame which is made by natural marble, and a spindle with the highest rotational speed $80,000 \mathrm{rpm}$. The micro-milling tool used in this study is $0.6 \mathrm{~mm}$ diameter uncoated two-teeth flat carbide end mills. The work piece is titanium alloy board with thickness of $8 \mathrm{~mm}$. The MQL system is Bluebe FK type with the oil rate $10 \mathrm{mml} / \mathrm{h}$ at the air pressure of $0.4 \mathrm{MPa}$. The type of cutting fluid is Bluebe LB-1 which is vegetable oil.

The cutting experiments are slot milling by two micro-mills. The details of cutting conditions in this study are listed in Table 1. The experiments were orthogonal experiments with two factors and four levels. The experimental parameters were listed in Table 2. Tool wear condition is examined when mill passes $90 \mathrm{~mm}$ long at workpiece. The values of tool wear are measured by Keyence microscope VHX-500 FE. The surface roughness was measured by Keyence 3D laser microscope VK-X100. The SEM photos are captured by JSM 6440. The direction of cutting fluid is shown in Figure 2. 
Figure 1 Experimental setup (see online version for colours)

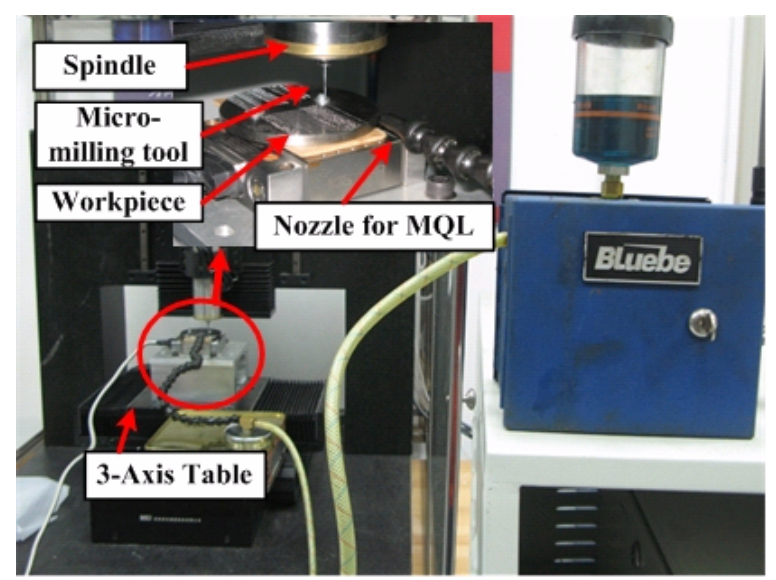

Table 1 Cutting conditions

\begin{tabular}{ll}
\hline Tool diameter & $\mathbf{0 . 6} \mathbf{~ m m}$ \\
Tool material & Tungsten carbide \\
Workpiece material & Ti6Al4V \\
Spindle speed & $40,000 \mathrm{rpm}$ \\
Feed rate & $1-2 \mathrm{~mm} / \mathrm{s}$ \\
Depth of cut & $100 \mu \mathrm{m}$ \\
Air pressure & $0.15-0.45 \mathrm{MPa}$ \\
oil supply rate & $10 \mathrm{ml} / \mathrm{h}$ \\
Distance between mill and nozzle & $40 \mathrm{~mm}$ \\
Fluid angle & $0^{\circ}, 90^{\circ}, 180^{\circ}, 270^{\circ}$ \\
\hline
\end{tabular}

Figure 2 Schematic diagram of fluid direction

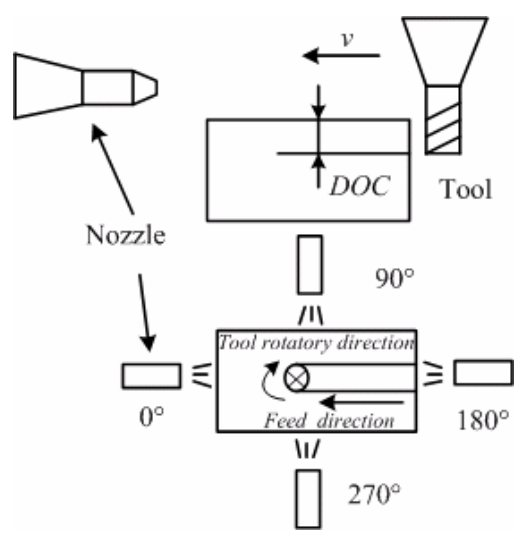


Table 2 Experimental parameters with orthogonal experimental design

\begin{tabular}{lcc}
\hline No. & Air pressure $(\mathrm{MPa})$ & Fluid direction $\left.^{\circ}{ }^{\circ}\right)$ \\
\hline 1 & 0.15 & 0 \\
2 & 0.15 & 90 \\
3 & 0.15 & 180 \\
4 & 0.15 & 270 \\
5 & 0.25 & 90 \\
6 & 0.25 & 0 \\
7 & 0.25 & 270 \\
8 & 0.25 & 180 \\
9 & 0.35 & 180 \\
10 & 0.35 & 270 \\
11 & 0.35 & 0 \\
12 & 0.35 & 90 \\
13 & 0.45 & 270 \\
14 & 0.45 & 180 \\
15 & 0.45 & 90 \\
16 & 0.45 & 0 \\
\hline
\end{tabular}

\section{Results and discussions}

\subsection{Tool wear analysis}

Tool wear of mill involves flank wear and rake face wear. Figure 3 shows the measurement method of tool wear marked. Figure 4 shows that the tool wear under MQL is smaller than that of dry cutting, which results in a longer tool life. At the end of cutting, flank wear under MQL condition was $45.7 \mu \mathrm{m}$ while $69.6 \mu \mathrm{m}$ under dry condition, as shown in Figure 4. These results show that MQL significantly improves the tool life especially the flank wear as flank wear has great influence on surface quality.

Figure 3 Tool wear measurement, (a) new tool (b) worn tool (see online version for colours)

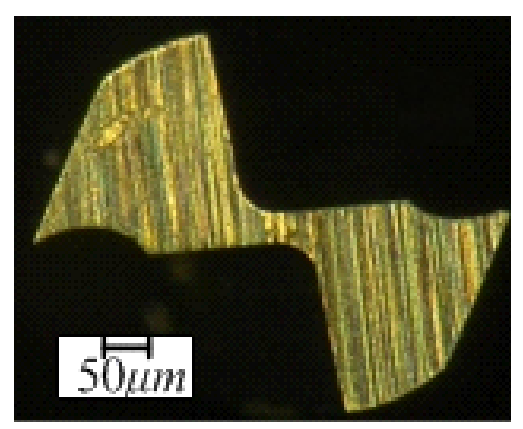

(a)

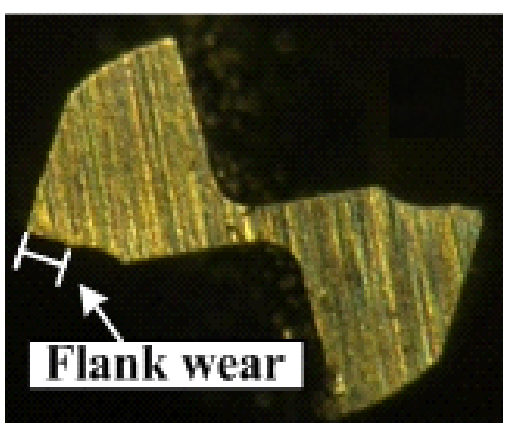

(b) 
Figure 4 Tool flank wear curves of micro-mill (rotational speed 40,000 rpm, depth of cutting 30 $\mu \mathrm{m}$, feedrate $2 \mathrm{~mm} / \mathrm{s}$ )

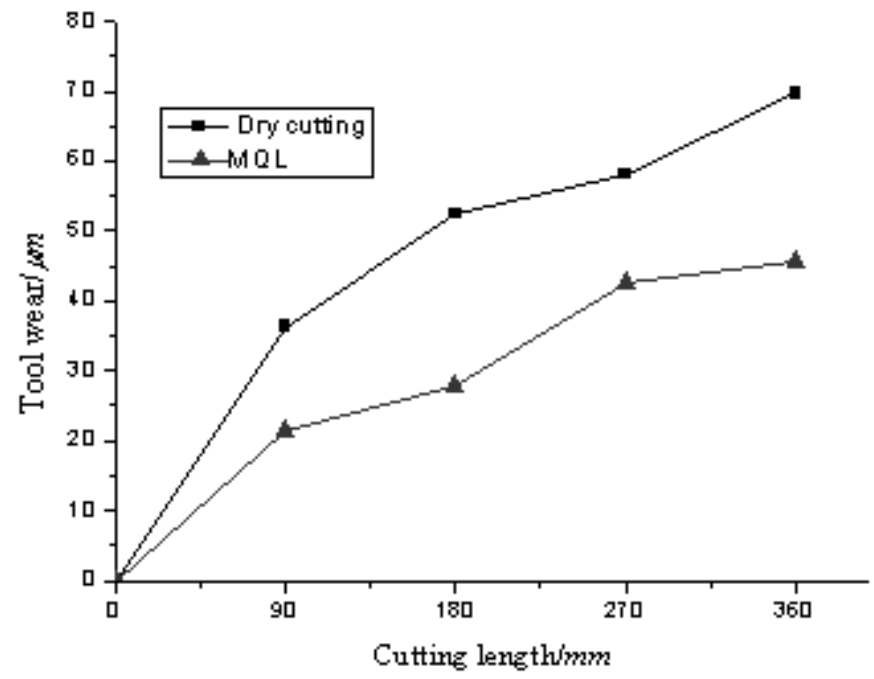

As shown in Figure 5, the wear of tool under dry condition is larger than that under MQL condition. In addition, under dry cutting condition, chip adhesion can be observed at tool tip as shown in Figure 5(a), while this phenomenon is not found under MQL condition. It can be inferred from above that the MQL condition has obvious effect on improving the tool life of tool. This also fully illustrates MQL can significantly increase machining performance and prolong tool life of cutting tool. This is mainly because the MQL oil mist has good ability in reducing the wear due to its performances of lubrication. And it can also reduce the tool-chip contact length which further improves the tool wear condition.

Figure 5 SEM photos of worn tools (cutting length $360 \mathrm{~mm}$, rotational speed 40,000 rpm, depth of cutting $10 \mu \mathrm{m}$, feedrate $2.1 \mathrm{~mm} / \mathrm{s}$ ), (a) dry cutting (b) MQL

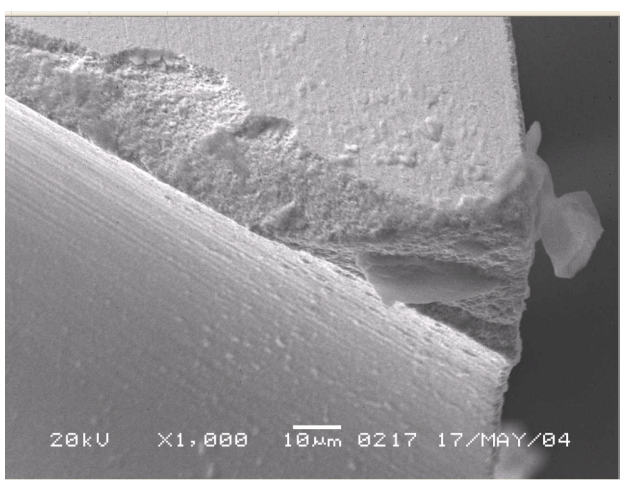

(a)

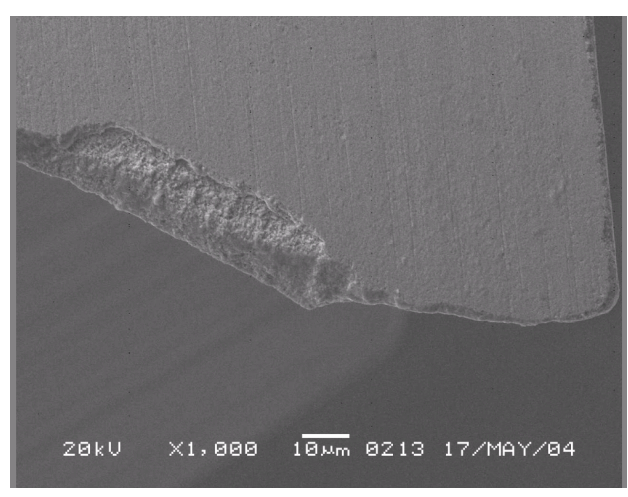

(b) 
SEM of wear and EDS analysis of typical area of the tool in MQL cutting condition were shown in Figure 6. It is notable that tool wear is more evenly distributed along the cutting edge. Adhesive wear is also found under MQL condition through the EDS analysis which is shown in Figure 6. From EDS photograph we can see that the main composition of the bonding layer is titanium element, and no oxygen element is found, which indicates that oxidation reactions have not occurred yet. The clusters of bonding properties pile up in the tool surface which have impede high-speed oil jet from reaching the cutting zone. Although these bonding properties have played effective role of no-oxygen protection, the tool wear becomes more severe due to the high temperature of the cutting zone, resulting in the minor effects of lubricants and ineffective heat-dispersion. From the analysis above, it is confirmed that MQL condition can dramatically improve the cutting performance and tool life. Adhesive wear not oxidation wear is found to be the main wear types in MQL cutting condition rather than oxidation wear.

Figure 6 EDS analysis results of MQL condition (see online version for colours)

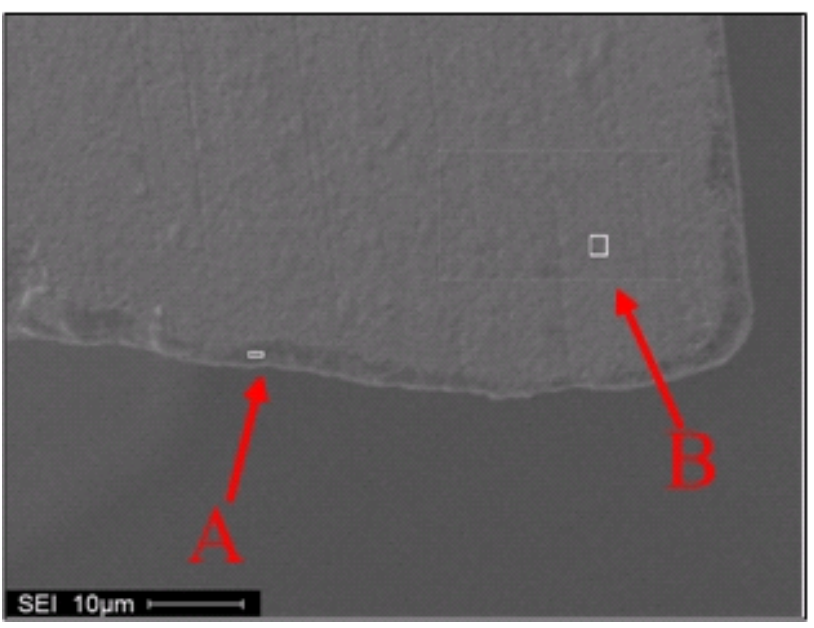

\begin{tabular}{|c|c|c|}
\hline Element & Whs & Ars \\
\hline CK & 21.10 & 70.18 \\
\hline$\pi K$ & 17.54 & 14.63 \\
\hline $\mathrm{CoK}$ & 04.03 & 02.73 \\
\hline$W L$ & 57.33 & 12.46 \\
\hline Matrix & Correction & ZAF \\
\hline Element & Wrs & Ats \\
\hline$C K$ & 11.66 & 62.17 \\
\hline$T i K$ & 01.82 & 02.43 \\
\hline $\mathrm{CoK}$ & 07.15 & 07.76 \\
\hline$W L$ & 79.37 & 27.64 \\
\hline Matrix & Correction & ZAF \\
\hline
\end{tabular}

\subsection{Cutting vibration}

Cutting vibration may lead to poor surface quality and rapid tool wear. The machine tools for micro-cutting are low rigid and will be easily influenced by external disturbance. Figure 7 presents the FFT frequency analysis of the cutting vibration signals for micro-milling under different air fluid angles. It can be observed that the biggest amplitude appears at about $1,880 \mathrm{~Hz}$ and $8,100 \mathrm{~Hz}$ among four cutting conditions, but the values of amplitude at these two frequencies are different when fluid direction changes. The amplitudes in Figure 7(b) and Figure 7(d) are smaller than that of other conditions. The lower amplitude implies the lower vibration and better surface quality. The results of surface qualities under different fluid direction will be discussed in the following parts. 
Figure 7 FFT analysis on cutting vibration signals with air pressure $0.35 \mathrm{MPa}$, rotational speed $60,000 \mathrm{rpm}$ and axial $D O C 30 \mu \mathrm{m}$, (a) fluid angle $180^{\circ}$ (b) fluid angle $270^{\circ}$

(c) fluid angle $0^{\circ}(\mathrm{d})$ fluid angle $90^{\circ}$

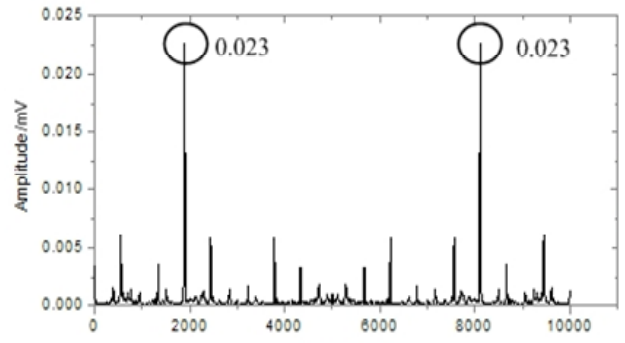

(a)

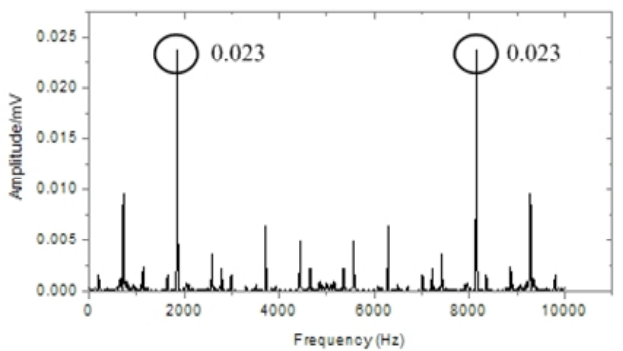

(c)

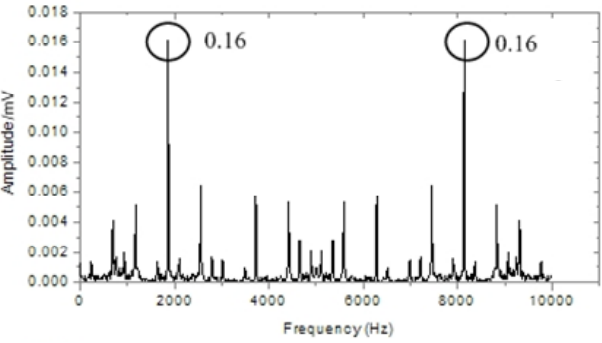

(b)

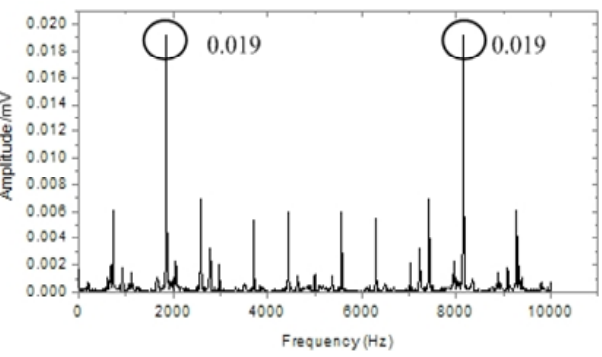

(d)

\subsection{Surface roughness}

Surface finish is an important index of evaluating machining quality. Poor surface finish decreases the tolerance of micro-components and lead (leads) to surface cracks of subsurface. Surface finish can be reflected by surface roughness. The smaller surface roughness means better surface finish. In order to reduce the machining time on further finish process, smaller surface roughness is expected in micro-machining.

Figure 8 Surface roughness vs. air pressure (rotational speed: 60,000 rev/m; DOC: $100 \mathrm{~mm}$; feedrate: $1 \mathrm{~mm} / \mathrm{s}$ ) (see online version for colours)

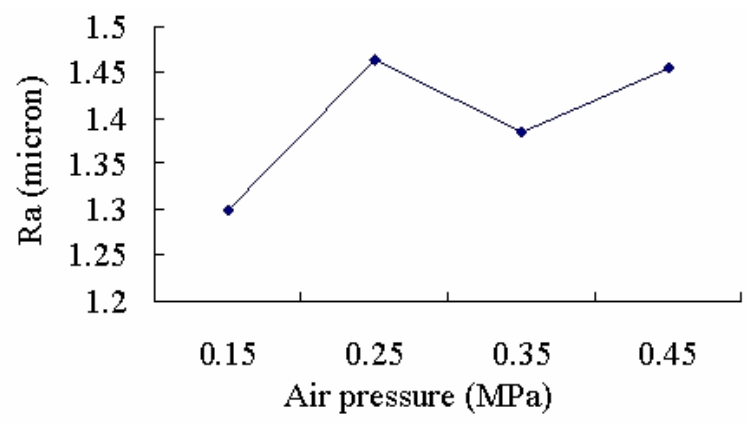


Figure 8 shows the surface roughness of bottom face of slot under different air pressures. It is shown that the surface roughness under the lowest air pressure $0.15 \mathrm{MPa}$ is up to $1.3 \mu \mathrm{m}$ which is smaller than that of the other pressures. The surface roughness under air pressure $0.25 \mathrm{MPa}$ and $0.45 \mathrm{MPa}$ are over $1.45 \mu \mathrm{m}$. These experimental results show that higher air pressure will induce higher surface roughness. Additional tool vibration caused by air fluid may increase surface roughness. The vibration analysis was discussed in Section 3.2 .

Figure 9 shows the surface roughness of bottom face of slot under different fluid directions. It is shown that the surface roughness under fluid direction of $0^{\circ}$ is $1.3 \mu \mathrm{m}$ which is smaller than other directions. As discussed in the above section, the vibration amplitudes under fluid direction of $0^{\circ}$ and $180^{\circ}$ are bigger than that of the other two directions, but the surface roughness under the fluid direction of $0^{\circ}$ and $180^{\circ}$ is smaller than that of the other two directions. In fact, the air fluid applies an additional vibration to the micro-tool which can reduce surface roughness like vibration-assisted micro-machining does.

Figure 9 Surface roughness vs. fluid direction (rotational speed: 60,000 rev/m; DOC: $100 \mathrm{~mm}$; feedrate: $1 \mathrm{~mm} / \mathrm{s}$ ) (see online version for colours)

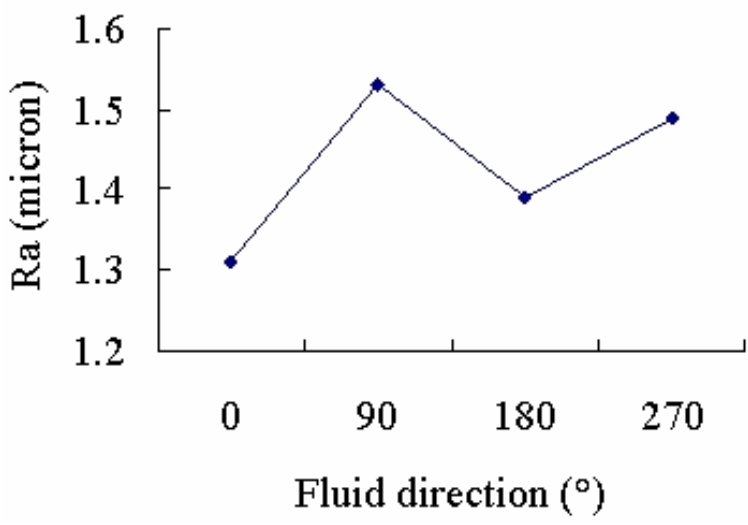

\subsection{Burr formation}

Burr formation limited the use of micro-cutting technology in industry. In order to decrease burr formation, cutting parameters should be optimised. In slot milling, burr formation is different at two sides. The burr height at the side of down-milling is higher than that of the other side. Figure 10 shows the shape of burrs in the study, serious burr and slight burr can be clearly observed by naked eyes. Experimental results show that air pressure has certain influence on burr formation. High pressure will induce serious burr formation. The burr formation under different air pressures and air fluid directions is listed in Table 3. Experimental results show that air pressure has great influence on burr size. The burr formation under air pressure of $0.15 \mathrm{MPa}$ is slight but serious under $0.45 \mathrm{MPa}$. However, $0.15 \mathrm{MPa}$ is not suitable for generating oil-air mist, the coolant is only caused by low speed air fluid. Furthermore, the burr formation under flow direction of $270^{\circ}$ is better than that of $180^{\circ}$ when air pressure is $0.35 \mathrm{MPa}$. The reason for different experimental results may be due to the vibration caused by air fluid. Low rigid system is 
easily disturbed by external disturbance. Different parameters of MQL will induce different disturbances. In the above discussion, the fluid direction of $0^{\circ}$ and $180^{\circ}$ induces the smaller amplitude in FFT analysis. So, the vibration under this condition is smaller than other fluid directions.

Figure 10 Burr formation (see online version for colours)

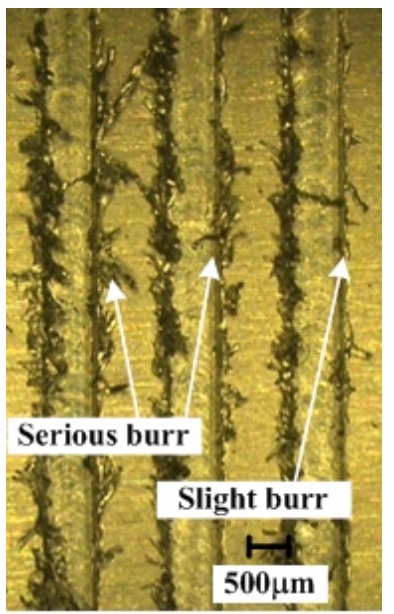

Table 3 Burr formation under different air pressure and fluid direction

\begin{tabular}{lllccc}
\hline Burr formation & \multicolumn{5}{c}{ Air fluid direction $\left(^{\circ}\right)$} \\
\cline { 1 - 5 } \cline { 3 - 5 } Air pressure $(\mathrm{MPa})$ & & 0 & 90 & 180 & 270 \\
\hline 0.15 & $\mathrm{l}$ & 1 & 1 & 1 \\
0.25 & $\mathrm{~S}$ & 1 & 1 & 1 \\
0.35 & $\mathrm{~S}$ & $\mathrm{~s}$ & $\mathrm{~s}$ & 1 \\
0.45 & $\mathrm{~S}$ & $\mathrm{~s}$ & $\mathrm{~s}$ & $\mathrm{~s}$ \\
\hline
\end{tabular}

Note: 1: slight burr formation, s: serious burr formation.

\section{Conclusions}

MQL is an eco-friendly and low cost coolant method. In this paper, the effects of MQL on tool wear, surface roughness, burr formation and tool vibration in the micro-milling of Ti6Al4V in contrast with dry cutting are studied. The experimental results showed that the effects of air pressure and fluid direction on milling qualities were confused. So, the optimisation of milling parameters should consider the purpose of optimisation. For example, if the purpose of optimisation is to reduce burr formation, low air pressure with proper fluid direction is suggested. The following conclusions can be drawn from these studies:

1 MQL significantly improves tool life. At the end of cutting, flank wear under MQL condition was $45.7 \mu \mathrm{m}$ while $69.6 \mu \mathrm{m}$ for dry cutting. 
2 The tool wear of micro-milling titanium alloy is mainly caused by material adhesion. SEM photos and EDS results show that chip adhesion is serious in dry cutting but seldom in MQL, so MQL has good lubrication ability for titanium micro-milling. EDS results shown that no oxidation wear was found in cutting zone. So MQL method can effectively reduce cutting temperature in cutting zone.

3 Air pressure and fluid direction have significant effect on surface roughness. The surface roughness under air pressure $0.15 \mathrm{MPa}$ and $0.35 \mathrm{MPa}$ is smaller than that of other pressures. Meanwhile, the surface roughness under fluid direction of $0^{\circ}$ and $180^{\circ}$ is smaller than that of other directions.

4 FFT analysis shows that the different air fluid directions induce different amplitudes. The amplitudes at fluid direction of $180^{\circ}$ and $0^{\circ}$ are bigger than that of $270^{\circ}$ and $90^{\circ}$. Experimental results show that burr formation is smaller when fluid direction is $270^{\circ}$.

5 Air fluid direction and air pressure have certain influence on burr formation. Burr formation will remarkably increase under higher air pressure. The burr size under air fluid direction of $270^{\circ}$ is smaller than that of other directions. Higher pressure will lead to a bigger burr size. The burr size under $0.45 \mathrm{MPa}$ is the biggest than that of other air pressures.

\section{Acknowledgements}

The work is supported by the National Natural Science Foundation of China (No. 50935001), National Key Basic Research Program under grant (No. 2011CB706804), Key Project of Shanghai Jiao Tong University (YG2012ZD07).

\section{References}

An, Q.L., Fu, Y.C. and Xu, J.H. (2010) 'A new technology on enhancing heat transfer during grinding of titanium alloy', Industrial Lubrication and Tribology, Vol. 62, No. 3, pp.168-173.

An, Q.L., Fu, Y.C. and Xu, J.H. (2011) 'Experimental study on turning of TC9 titanium alloy with cold water mist jet cooling', International Journal of Machine Tools and Manufacture, Vol. 51, No. 51, pp.549-555.

Bao, W.Y. and Tansel, I.N. (2000) 'Modeling micro-end-milling operations. Part III: influence of tool wear', International Journal of Machine Tools and Manufacture, Vol. 40, No. 15, pp.2193-2211.

Boyer, R.R. (1996) 'An overview on the use of titanium in the aerospace industry', Materials Science and Engineering, Vol. A213, No. 1, pp.103-114.

Chae, J., Park, S.S. and Freiheit, T. (2006) 'Investigation of micro-cutting operations', International Journal of Machine Tools and Manufacture, Vol. 46, No. 3, pp.313-332.

Ezugwu, E.O. and Wang, Z.M. (1997) 'Titanium alloys and their machinability - a review', $J$. Mater. Process Technol., Vol. 68, No. 3, pp.262-274.

Fleischer, J., Schulze, V. and Kotschenreuther, J. (2009) 'Extension of cutting force formulae for microcutting', CIRP Journal of Manufacturing Science and Technology, Vol. 2, No. 1, pp.75-80. 
Ghai, I., Wentz, J., DeVor, R.E., Kapoor, S.G. and Samuel, J. (2010) 'Droplet behavior on a rotating surface for atomization-based cutting fluid application in micromachining', Journal of Manufacturing Science and Engineering, Vol. 132, No. 1, p.011017.

Ibrahim, R., Bateman, R., Cheng, K., Wang, C. and Au, J. (2011) 'Design and analysis of a desktop micro-machine for vibration-assisted micromachining', Proceedings of the Institution of Mechanical Engineers, Part B: Journal of Engineering Manufacture, Vol. 225, pp.1377-1391

Jemielniak, K. and Arrazola, P.J. (2008) 'Application of AE and cutting force signals in tool condition monitoring in micro-milling', CIRP Journal of Manufacturing Science and Technology, Vol. 1, No. 2, pp.97-102.

Jun, M.B.G., Joshi, S.S., DeVor, R.E. and Kapoor, S.G. (2008) 'An experimental evaluation of an atomization-based cutting fluid application system for micromachining', Journal of Manufacturing Science and Engineering, Vol. 130, No. 3, p.031118.

Li, K-M. and Chou, S-Y. (2010) 'Experimental evaluation of minimum quantity lubrication in near micro-milling', Journal of Materials Processing Technology, Vol. 210, No. 15, pp.2163-2170.

Mian, A.J., Driver, N. and Mativenga, P.T. (2011) 'Identification of factors that dominate size effect in micro-machining', International Journal of Machine Tools and Manufacture, Vol. 51, No. 5, pp.383-394.

Nam, J.S., Lee, P.H. and Lee, S.W. (2011) 'Experimental characterization of micro-drilling process using nanofluid minimum quantity lubrication', International Journal of Machine Tools and Manufacture, Vol. 51, No. 7, pp.649-652.

Novakov, T. and Jackson, M.J. (2009) 'Chatter problems in micro- and macrocutting operations, existing models, and influential parameters - a review', The International Journal of Advanced Manufacturing Technology, Vol. 47, Nos. 5-8, pp.597-620.

Saptaji, K., Subbiah, S. and Dhupia, J.S. (2012) 'Effect of side edge angle and effective rake angle on top burrs in micro-milling', Precision Engineering, Vol. 36, No. 3, pp.444-450.

Simoneau, A., Ng, E. and Elbestawi, M.A. (2006) 'Chip formation during microscale cutting of a medium carbon steel', International Journal of Machine Tools and Manufacture, Vol. 46, No. 5, pp.467-481.

Vogler, M.P., DeVor, R.E. and Kapoor, S.G. (2004) 'On the modeling and analysis of machining performance in micro-endmilling, part I: surface generation', Journal of Manufacturing Science and Engineering, Vol. 126, No. 4, p.685.

Woon, K.S., Rahman, M., Fang, F.Z., Neo, K.S. and Liu, K. (2008) 'Investigations of tool edge radius effect in micromachining: a FEM simulation approach', Journal of Materials Processing Technology, Vol. 195, No. 1, pp.204-211.

Yun, H.T., Heo, S., Lee, M.K., Min, B-K. and Lee, S.J. (2011) 'Ploughing detection in micromilling processes using the cutting force signal', International Journal of Machine Tools and Manufacture, Vol. 51, No. 5, pp.377-382. 